Towards re-defining communication skills courses at Sokoine University of Agriculture: Lessons from selected African universities

\author{
Komba, Sotco Claudius $₫$ \\ Sokoine University of Agriculture, Tanzania (sotratz@yahoo.com) \\ Mohamed, Hashim Issa \\ Sokoine University of Agriculture, Tanzania (mohhashim@gmail.com)
}

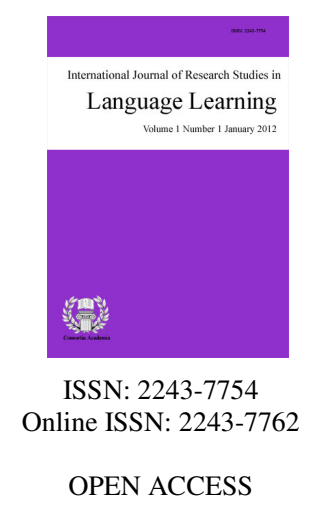

Received: 29 February 2016

Revised: 9 March 2016
DOI: $10.5861 /$ ijrsll.2016.1478

Available Online: 9 May 2016

Accepted: 28 April 2016

\title{
Abstract
}

Tanzanian universities, including Sokoine University of Agriculture, have been offering Communication Skills courses in addressing students' language and communication needs. Despite this initiative, there have been some concerns from both students and lecturers that the teaching of Communication Skills courses has little impact on students' development of English language and communication skills. In response to this view, the Department of Social Sciences, at Sokoine University of Agriculture, conducted a study to collect information from an international perspective on the best practices in English language and Communication Skills programs. The study involved five universities found in two African countries: Three universities from South Africa and the other two from Ghana. Data were collected through interviews, checklists and review of documents and were analyzed using thematic analysis. Although there were some similarities in the ways English language and Communication Skills courses are offered in the visited countries and at Sokoine University of Agriculture, the findings revealed that there were better practices in the visited countries in terms of administration, curricula, and utilization of resources, which have an implication on the conduct of Communication Skills courses at Sokoine University of Agriculture and other Tanzanian universities.

Keywords: communication skills courses; Tanzanian universities; medium of communication 


\section{Towards re-defining communication skills courses at Sokoine University of Agriculture: Lessons from selected African universities}

\section{Introduction}

According to the Tanzanian Education and Training Policy of 2014, English has been (and is still) used as a medium of instruction in post primary education. Kiswahili, which is the national and official local language, spoken by over $90 \%$ of the population, is compulsory in the primary education as a language of instruction, while English is taught as a subject from grade 3 (Ethnologue, 2005; URT, 2014). At primary school level, there is no such thing as English being used in communication. That is, students are taught about English language, but they are not given opportunities to use it in communication. At secondary school level and above, where English is used as a medium of instruction, language absurdities have continued to permeate classroom discourse, generating huge challenges in the Tanzanian education system.

Furthermore, English is an official language, but its official status as a second language in Tanzania, is only significant in the field of education as the medium of instruction from secondary school and above, as explained above. Outside the education system, English is the language of the minority group spoken by only a small percentage of the population. The language use in the wider community is limited to international relations and trade; business; tourism; mass media (e.g. newspapers, Radio and TV stations); higher courts of law; and information technologies (e.g. internet services), though such services are still concentrated in the urban areas. The limited use of the language in public domains, raises questions as to whether English qualifies to be an official second language in Tanzania. There is a plethora of literature documenting constraints in the use of English language for communication in secondary schools and universities in Tanzania (Qorro, 1999, Brock-Utne, Desai, \& Qorro, 2003, 2005; Mohamed, 2005, 2006).

Weaknesses in the English language and English communication skills are an obstacle to making Tanzanian graduates competitive in the highly fragile job market in the region. It is also apparent that poor competences in languages have been affecting the performance of students in examinations in Tanzania, and which can also be linked to a negative influence on the youth's interest in science subjects/disciplines, which are already viewed as unattractive, partly because of high failure rates. This, certainly, undermines the national strategies for the use of Science, Technology and Innovation (STI) in development. Thus, the sustainable use of STI in development in Tanzania will certainly hinge on building capacities in communication skills so as to enable students follow and understand science concepts and to be able to pass examinations.

These challenges call for institutional and national strategies that will ensure that competencies in communication skills are promoted in order to strengthen the quality of education. Communication Skills course was introduced at Sokoine University of Agriculture (SUA) under the Communication Skills Unit (CSU) when SUA was still the Faculty of Agriculture, Forestry and Veterinary Sciences (FAFVS) of the University of Dar es Salaam (Mohamed, 2006). The purpose of the course was, first, to teach general study skills to all undergraduate students, and second, to teach other language skills such as grammar to students who proved to be too weak in the English language to be able to follow other university courses. Thus, the unit designed an Intensive Grammar Program (IGP) to address students' grammar problems, and a Communication Skills (CS) course to address students' communicative problems. IGP was a 2 week crush program to students who failed the University Screening Test (UST) which was administered to students upon their arrival at the University.

In 1987, SUA introduced the Communication Skills course under the Basic Sciences Unit, which was established for the purposes of offering courses on Basic Sciences to students whose other university courses demanded the commanding knowledge of Basic Science subjects (Komba, 2008). However, Communication Skills became one of the pioneering courses in the Unit, and which was conducted as a 2 week pre-session and 
Towards re-defining communication skills courses at Sokoine University of Agriculture

non- examinable course. In 1994, the FoA made Communication Skills an in-session and examinable course after the realization that in its former structure the course was not having any impact on improving students' language and communicative competence. However, students in other faculties continued to follow the course as a pre- session and non-examinable for a short while.

In 2000, the Basic Sciences Unit was elevated into the Faculty of Science, and Communication Skills became one of the courses offered in the Department of Social Sciences, under the faculty of Science (Komba, 2008; Mohamed, 2006). This development was soon followed by the change of the university academic system from term to semester system. The change was implemented through a review of the curricula across the university faculties to make them fit into the new semester system. Under the semester system, Communication Skills was made a mandatory and examinable course across faculties and contributing 2 credits of the 12 credits required as a minimum to be accumulated by a student in any one semester. The course, however, continued to be offered to students in the first semester of their first year whereby students used to meet only twice to thrice per week for a total of 75 hours for the entire academic year. Thus, the Department had been largely compelled to turn these sessions into crash program, involving issues of general grammar, listening, speaking, writing, reading and general aspects of study skills. Similar experience is also common in other universities in Tanzania (See Ndoloi, 1990, Rugemalira, 1990 for experiences at the University of Dar es Salaam).

Given that the structure and conduct of Communication Skills course was found ineffective, the Department proposed the restructuring of the course into two components: Communication Skills I (SC 100) and Communication Skills II (SC 101). The proposal was approved by Senate and this structure has been under implementation since 2008/9 academic year. The Communication Skills I entails Language and Grammar and it is offered in the First, Third, and Fifth semesters as an elective but mandatory to only those classified as poor in English, upon taking the University Screening Test. It is an elective course in the Third and Fifth semesters to allow a student a maximum of three attempts before he/she is deemed to have completely failed the course. The course assessment has been on Pass or Fail basis, that is, examinable but with no credit. However, if a candidate fails to pass the examination in the third attempt, a fail grade is indicated in the final transcript.

The Communication Skills II course is on Academic Study skills. This course is a compulsory 2-credit course, offered in the Second Semester for all undergraduate students. This course is offered on assumption that at this time most (if not all) students would have acquired appreciable knowledge of English to enable them benefit from communication skills studies and thus participate meaningfully in the application of such knowledge in other university courses.

Despite all the efforts to restructure the course, complains from both students and teachers have continued and all of these have pointed out on the ineffectiveness of the Communication Skills courses in addressing students' language and communication challenges. Communication Skills courses were meant to respond to specific and or respective academic communication needs. However, students' language and communication problems have been reported to increase among the majority of students (save for those with good language background from English medium primary and secondary schools) and that University students have been increasingly failing to cope with the technical and scholastic demand made on their use of language as students. This scenario was thought to have negative impacts on the university delivery systems, and thus undermining the university efforts to offer quality education to its graduates.

In response to this situation, the Department of Social Sciences, in collaboration with the Innovative Agricultural Research Initiative (iAGRI) program conducted a study in 2014 to gather information on best practices in the conduct of Communication Skills courses and English language programs from other universities in the region. The study sought to answer one main research question: How do other African universities run English and Communication Skills courses? Therefore, this study was intended to explore useful lessons which SUA and other universities in Tanzania could learn to improve the teaching of Communication Skills courses and thereby supporting the provision of quality education in Tanzania. 


\section{Methodology}

This study was conducted in two African countries: South Africa and Ghana. South Africa was identified on the basis that English, which is a medium of communication in education, is taught in an environment where many other languages besides English are used in students' day-to-day communication. This is consistent with the situation in Tanzania, where English is the medium of instruction in a predominantly Kiswahili speaking environment. Furthermore, South Africa has some of the largest universities in Africa with long experience and requisite technology in implementing English language programs. For the second country, Ghana was selected because it provides both a contrast to South Africa in terms of development and similarities to Tanzania in terms of technological and sociolinguistic characteristics. Many other countries met this criterion. However, Ghana was preferred because it has many salient features which other African countries did not seem to have. First, Ghana uses English in her education system, but so does Kenya and Uganda. However, Kenya and Uganda are multilingual societies whose linguistic diversities make English a necessary neutral language of communication not only in a classroom but also even outside the classroom. In Ghana, however, Twi and Fante, (the dialects of Akan) are the dominant local languages, and they are used in the outside community, as is the case for Kiswahili for Tanzania. Therefore, Tanzania has more in common with Ghana linguistically than with both Kenya and Uganda.

A total of five (5) universities, including three University from South Africa [i.e. Tshwane University of Technology (TUT), University of Pretoria (UP), and the University of Limpopo (UL)] and the other two from Ghana [i.e. University of Cape Coast (UCC) and University of Ghana (UG)] were involved. The choice of these universities was based on the following criteria: First, the presence and innovativeness of English-language teaching programs and resource centres, and secondly, experience in implementing Communicative Language Teaching methodologies. The other criterion was the use of ICT and e-learning in fostering language teaching and learning.

Data collection was mainly done through interviews, checklists, review of documents and classroom observations. Face to face interviews with staff and students were conducted to inquire information on the conduct of Communication skills courses. In addition, specially designed observation templates were used to collect information from physical tours of language resource centers. Lastly, documentary review was employed to gather information on curricula, teaching approaches, and teaching and learning materials in use. The collected data were analyzed using thematic analysis approach, addressing the broad themes of administration, teaching staff, curricula and teaching materials, and resources, which were of specific relevance to SUA.

\section{Findings and discussion}

\subsection{Administrative structure}

Administrative structures at five of the universities entails the presence of either departments, language units or centres. At the University of Pretoria, however, apart from the Language Unit, there are other two wings namely the Translation and Interpretation Unit and the Writing Centre, which also work closely with the Language Unit, but dealing with postgraduate teaching. The Language Unit deals with undergraduate teaching. In all the other universities, language and communication are offered in the language designated departments or centres. Additionally, the terminology used to refer to language and communication studies varied across the universities visited. The universities in Ghana and the University of Limpopo use the term Communication Skills, which is also used at SUA and other Tanzanian universities. The other two universities in South Africa use the term Academic Literacy.

\subsection{Program structure and curricula}

Language programs offered in all the visited universities emphasize more or less on similar skills, with 
reading and writing as a primary focus. In some universities, however, a distinction is made between general English and English for academic purposes, the former referring to basic English skills, such as grammar, and the latter referring to academic literacy skills. Where the distinction is made, the two courses are offered in separate semesters, Tshwane and Limpopo serving good examples in this arrangement. Other universities' language program structures are more or less similar to the one at SUA, where Communication Skills course runs for two semesters in the first year, focusing on specific skills in each semester. One major difference between SUA and all the universities visited, however, is that in both semesters, Communication Skills are required and that students cannot register for courses in the next semester if they fail Communication Skills. At SUA, Communication Skills I is a guided elective but not credited, offered to those who fail the Screening Test. Communication Skills II is the only course required for all first-year students. Also at SUA, there is no discipline-specific course content, meaning that the same Communication Skills I and Communication Skills II materials are offered to all faculties irrespective of students' disciplines. This could be one of the areas which need to be addressed in making Communication Skills I work better for students at SUA. At its current status of zero credit at SUA, the course seems to be unattractive to both categories of students, that is those who pass the UST and thus the course becoming a guided elective to them (these do not elect the course because they see the course as not having any value addition) and those who fail the UST making the course mandatory to them (these only attend the curse just to pass examinations but they do not have any keen interest in studying the course).

Several universities also offer a separate English Proficiency Program, which is a non-degree language program offered on-demand to different categories of clients. Both universities in Ghana offer these programs, which run up to a year. The University of Ghana caters for students from Burkina Faso, and also offers Special English courses on request to in-country clients, such as companies that enrol their employees in tailor-made training for specific language needs, especially speaking skills. Specially, the Language Centre at the University of Ghana runs English Proficiency Programs such as English for AngloGold Ashanti employees, English for Samsung employees, English for PhD students, English for agriculture students, English for Law students, just to mention a few. The University of Cape Coast runs similar courses, but for the moment they cater for students from non-English speaking countries in West Africa. Also, English foundation courses which are specifically designed for basic-level English language learners are a common phenomenon in South African universities.

\subsection{Teaching methodology}

The teaching methodology in all the universities is drawn from a learner centered approach and group work activities are the major means to achieve instructional objectives. This practice is in line with a paradigm shift of English Language teaching approaches, where the focus has changed from what the teacher does to what the learners will be able to do in what is now called communicative language teaching (see Richards, 2001; Brown, 2015). In South Africa (especially at TUT and UP), instructors are assigned to a subject area, and the department does its best to keep instructors in the same subject so that they can develop a specialization over time. In practice, this is often difficult due to high labour turnover. However, it is worth mentioning that efforts are usually made to ensure that language programs are designed and offered on discipline specific basis and that the content is customized to address needs of a particular discipline. For example, at UP there are Academic Literacy Skills programs for Health Sciences, Law, Humanities, and so on. Customization is also present in course materials, which are tailored to include subject-specific content. A similar scenario was observed at TUT, where for example they have Communication Skills for Engineers.

Customized language programs were also present in Ghana, but to a lesser extent than in South Africa. At the University of Ghana, only the second semester of language instruction includes customized content. At the University of Cape Coast, a system similar to what exists at SUA is followed, where the same language content is delivered to students across university faculties irrespective of disciplines. Students are still clustered into language learning groups, but these are organized on the basis of availability of teaching staff and venues, and less so on the basis of students' areas of specialization. This has proven to be counterproductive at SUA and is 
Komba, S. C., \& Mohamed, H. S.

one of the areas that needs redefining.

Guided writing and Lecture style are also common practices at UL. The teaching situation is slightly different in Ghana where teaching assumes lecture format, but also emphasizes students' group work and Project based learning (PBL). Lecture method has been a predominant teaching approach at SUA; this is especially because large class sizes, time limitation and resource poor environment frustrate instructors' creativity of making Communication Skills sessions more participatory.

\subsection{Skills emphasized and use of resources}

Across the universities, all the four language skills (listening, reading, writing and speaking) are taught, but writing and reading skills are the most emphasized. The use of teaching resources varies from university to university. For more resourced universities like Pretoria, most venues have technology, such as projectors installed in every teaching venue. Pretoria has also a very responsive IT department that manages the systems and responds when users experience challenges. All three universities in South Africa have access to Blackboard, a leaning management system (LMS) but reported that most instructors use it primarily as a repository of lectures and readings.

In resource constrained situations, teaching certain skills, such as writing, becomes a challenge, especially in large classes. The same applies to reading, especially where reading materials are in short supply and students are not able to access reading materials and complete reading assignments before class. In such situations, universities have been banking on the dedication of individual instructors in giving additional instruction to students. At UCC for example, demonstrators (teaching assistants) schedule tutorials each week to give examples and exercises to students. In Ghana, especially at the University of Cape Coast, lecturers from other subject areas are also involved in grading students' works based on language. In other universities, especially in South Africa, involvement of lecturers from other subjects in this regard was reported as a challenge. Here, cooperation of lecturers from other subjects in addressing issues regarding language in grading and other matters was reported to be minimal. A similar trend could be said of SUA, and having more lecturers' grade on language would enhance some of the skills imparted in language classes.

\subsection{Students}

There is diversity in students' proficiency levels in universities in South Africa. Therefore, classes are for the most part mixed-levels. There are a small number of international students, especially at UP and TUT. Due to these complexities, the English course is compulsory to any newly-enrolled student. In Ghana, this diversity is not as broad, since students generally come from similar economic and social backgrounds, and for the most part students also share linguistic and education backgrounds. This situation is in many ways similar to the one existing in Tanzania, where students come from predominantly Kiswahili speaking communities, and sharing common education backgrounds. There are, however, some exceptions, especially with regard to students who come from affluent and elite families (these often have advantageous language and education background), but these are very few to have any significant impact in post-secondary education system.

Generally, in the institutions visited, students believe that English language proficiency is not a problem. This leads them to view Communication Skills courses primarily as an additional burden to their studies. However, instructors report that many students are struggling, especially with academic English. Nonetheless, students' attitudes towards English are positive. As a language, parents and students realize that English is what they need to get along in life, with their careers and in education. It is worth noting that in some parts of South Africa and Ghana, English is a problem because students' proficiency is very low due to poor preparation at lower levels. 


\subsection{Teaching staff profile}

In all the universities, staffing is a common problem, as the visited universities were characterized with a small number of permanent staff, supplemented by large numbers of part-time staff. The problem is often caused by either limited positions available for recruitment of permanent staff at the University or difficulties of getting individuals who meet minimum education qualifications. Most universities require candidates for permanent positions to possess a Master's degree in a relevant discipline. Universities resolve this by recruiting part-time staff. In the case of universities in South Africa, instructors with only an honours degree are hired due to difficulties of recruiting suitable Master's degree holders into part-time positions. Relying heavily on part-time staff brings its own challenges. One of these is high labour turnover caused by part-time instructors who constantly look for permanent jobs with better remuneration packages. The situation is more or less the same in Ghana. Both the University of Cape Coast and the University of Ghana have a small number of full-time staff and a large number of part-time staff. For example, at the University of Ghana there are six full-time lecturers and about 25 part-time staff at the Language Centre. This has made it possible for staff to teach between 2-5 groups of students in any given semester.

\subsection{Assessment}

In four of the universities, continuous assessment with a final exam is the preferred mode of assessment. The exception is the University of Pretoria where continuous assessment is used, but with no final examination. Continuous assessment tasks include an array of activities across universities, including quizzes, objectives tests, essays, and case study projects. Most of the continuous assessment materials are designed on the basis of individual instructors' discretion. Universities usually set a minimum number of assignments that can contribute to continuous assessment marks, but instructors can give as many assignments as they wish. However, in some universities, such as Limpopo, writing questions for tests given during the semester is challenging because there are not enough test venues and multiple versions of the exam are required. Grading is also a problem because of the number of students per class, so some instructors use peer grading.

The contribution of the continuous assessments to a final grade varies from one university to another; for example, continuous assessments contributes $60 \%$ and final exam $40 \%$ at UL (SA), while at the UG, midterm exam (their version of continuous assessment) is worth $30 \%$ and the final is worth $70 \%$ (See Table 1). At UG, class participation might also be taken into account, but only if a student fails the tests.

\section{Table 1}

Universities' marks distribution and pass mark for language courses

\begin{tabular}{cccc}
\hline Universities & Continuous assessment (\%) & End of semester exam (\%) & Pass mark $(\%)$ \\
\hline TUT & 40 & 60 & 50 \\
UP & 100 & NIL & 50 \\
UL & 60 & 40 & 50 \\
UCC & 40 & 60 & 50 \\
UG & 30 & 70 & 50 \\
\hline
\end{tabular}

The pass mark for all the universities is $50 \%$. Again in all the universities a pass is required for students to be allowed to register for courses in the next academic year. However, many universities also have systems in place to help struggling students pass. At UCC, for example, if students fail the Communication Skills Course in the first semester, they are allowed to continue to the second semester and sit for a supplementary exam which they must pass at the end of the second semester. If the student fails the course in the second semester as well, they will not be allowed to register for courses. At the UG, failing students must repeat and pass academic writing otherwise they are not granted a degree. At the UP students that fail are allowed to sit for a multiple choice exam which they must pass. 
Generally teaching staff at all the universities visited encounter more or less similar challenges in dispensing their duties. The main difference is the manner in which each university addresses these challenges.

Large class sizes - Large class sizes are an interestingly common problem in all universities visited, but with varying degrees. The average class sizes in universities in South Africa ranges from 50 to 200 students depending on the discipline. In Ghana, class sizes vary significantly between the two universities, while UG has an average class size of 50-80 students, at the UCC the class size is as high as 100 to 120 students per class. However, neither of these averages would be anything comparable to SUA where 200 to 300 students is the average class size for Communication Skills programs. This challenge is addressed differently across the universities. Some universities such as UCC and UG opt for putting students into smaller groups, which however exert more pressure on staff work load in terms of additional contact hours, increased number of smaller groups for staff to handle, and a requirement for additional venues and staff. At the UG for example, each level has around 60 groups. Students register online while selecting their preferred class schedule and where space is available. This is because groups cannot take more than a prescribed number of students. However, the university had to recruit more staff in order to reduce the number of students per class which has resulted into a more positive learning environment. Other strategies used across universities include giving students reading assignments before class, referring students to particular websites for self-study purposes, use of multiple choice questions to simply marking, group work, and use of tutorials/seminars using demonstrators and or teaching assistants.

Large class sizes - Classes with mixed ability students was reported as a potential problem, but many universities view the diversity of skill levels in each class as an asset as they can have groups mixed with more advanced students helping others. Staffs in Academic Literacy at the University of Pretoria for example have found that stigmatization and other factors make it preferable not to sort students on ability level and therefore instructors use group work to help students learn from one another. However, a unique challenge in this aspect is when the mixing is also to do with social backgrounds. A good example is the University of Limpopo, where most students come from rural areas where, besides language abilities, there are problems of priorities. In other words, investing in education becomes a challenge to most parents. Such students are likely to have poor concentration in class among other things.

Students' attitude towards language - Students' attitude towards language has not been consistent, even within individual universities. As reported earlier overall, students do not believe they need English language instruction even though instructors report that many students struggle with academic English. However, it was also reported that by their second year, students are often more receptive to English instruction because they have struggled and understand how academic English is a different skill. At the University of Limpopo, the instructors agreed that starting with popular literature and transitioning to academic materials is a good strategy to ease students into academic English. The Academic Writing Unit at the University of Pretoria reported to have opted for working with more authentic texts, awarding 6 credits for good performing students, and counselling students on the importance of soft skills. However, some of these strategies place a high administrative burden on the Unit. Truancy and absenteeism was also reported as a common problem at the University of TUT, especially for off campus students. The required attendance is $80 \%$ at the University. Swipe cards are used to monitor attendance, but there is a host of problems to get the system work; the problems revolve around social, geographical and family issues.

Reading culture - Poor reading culture has been reported across all the universities, and is attributed to a variety of reasons, ranging from poor reading skills (due to education background) to the availability of suitable reading materials. This is one reason students 'copy and paste' when given reading and writing assignments. Individual universities have been addressing this problem differently. The program 'Turn It In', which is an online plagiarism detector, is used at the University of Limpopo to address the problem of plagiarism. Thus, 
students are supposed to submit their work electronically. This could be a useful model at SUA, especially for marking students' Special Project reports and dissertations. Currently, matters regarding plagiarism have no clear guidelines at SUA, apart from a blanket label of 'cheating' as explained in examinations regulations. However, plagiarism can involve high-level breaches of ethics and protocol in academic writing in addition to simple cutting and pasting of materials.

The TUT opted to use English Word Power (EWP), a computer Software programme to test students on reading ability. However, the timing for the EWP tests is usually unfriendly, especially when the tests are to be administered late in the evening, and students have transport problems. The University tried to fix this by putting more tests on Fridays. As has been stated previously, many universities enhance student interest in reading by teaching authentic materials. At the University of Limpopo, for example, some instructors started with a collection of reading materials on popular literature for lending to students. Each student was assigned to read, write a report, and present it in class. This strategy was reported to be working well, although it involves a great deal of commitment on the part of instructors, especially if these instructors have to invest money from their personal incomes to finance the program.

Involvement of non-language instructors in helping students to learn English - Lack of cooperation of non-language instructors in helping students to learn English has been a common problem across all universities, with the exception of the University of Cape Coast. At the UG, instructors in other departments are encouraged to help their students understand the value of academic writing, but getting them to participate has been difficult. Most of them state that they are not language teachers and they are not responsible to deal with language matters. Similar cases were reported at the universities visited in South Africa. This situation is similar to SUA where non-language instructors see language-related problems in students' work as none of their business. At SUA, this attitude makes students feel that language is not an issue, because it has little bearing on their scores in other subjects.

Students support services - Students support services at TUT and Limpopo were provided by Centres for Academic Excellence (CAE). At TUT the CAE offers students an English tutoring program that meets once each week for students identified as needing additional support in this subject. Students are referred by instructors or the CAE but can also opt to join the class on their own. In addition to English support, the CAE provides counselling, mentoring, and other tutorials. At UL, the CAE reports directly to the Deputy Vice Chancellor, responsible for Academic Affairs, and is funded by the University. The centre supports both academic staff and students in providing training, tutoring, and counselling services and is staffed by instructors from different disciplines/backgrounds. Departments, including Language Department, submit their needs to the centre for intervention. At the UG, there is a large Language Centre that deals with matters pertaining to language. One of the roles of the centre is to develop manuals that incorporate materials to enhance the course outline. There is also an Academic Writing Resource Group where instructors can go to find additional materials.

Writing units were found in all universities which, among other things, help students to fine tune their writing such as a thesis/project, work and the like. The way the services at writing centres are rendered varies from university to university. At the UP for example, the staff/consultant only goes through a few paragraphs during a working session and then the students have to revise on their own, much more like a teaching strategy. At UCC, on the other hand, the student drops the document and the staff/consultant takes the document and provides edits. Once the document is edited, the consultant sits down with the client and explains the comments, but it is not an interactive editing session. While writing centre services are free at UP, those who use this service at UCC have to pay. The fee scale has different rates depending on the level of the student/faculty, but ranging from1-2 cedi per page. Some of this money goes to the unit and some goes to the reviewer/consultant. In the future, the UCC writing unit intends to organize training sessions on writing skills. At the University of Limpopo, the University's Centre for Academic Excellence is in the process of establishing a Writing Centre that will be supported by central administration. Senior students and postgraduate students at the University will be engaged as language consultants to run workshops and provide written reviews of student assignments. The service will 
be free, and students will be expected to submit a draft of their assignment for the consultants to review independently. Feedback will be provided in written format. The writing centre will have some resources available for students.

Classroom equipment - Variation was also noted in the availability of equipment in classrooms across the universities visited. At TUT a few venues have technology such as large projectors; however, most venues do not have such equipment so instructors carry projectors and public address systems to classes. At UP Most classrooms are equipped with audio/video equipment. At Limpopo Venues do not have projectors or technology. These must be carried by staff to the venues. In the past, some technology was available in the classrooms, but theft and vandalism are frequent and have prevented the administration from reinstalling equipment into the classrooms. At UCC, a few venues had projectors which were reported to be quite useful in language classrooms, and the university plans to install projectors in each classroom. Moreover all classrooms in the Multipurpose Language Complex, (MPLC) which is currently under construction, are intended to be equipped with state of art equipment for language instruction, such as computer work stations. The particular software they will utilize has not yet been determined. The Language Centre at the UG has four classrooms with audio visual facilities for language courses. One of these classrooms is dedicated to the English Proficiency Program. The other three are for regular English language instruction.

Language laboratories - All the universities visited have language laboratories equipped with computers for students use. The computer language tools which are made available to students varied from one university to another. TUT has two computer labs dedicated to English Word Power. English Word Power (EWP) is an online English instruction tool developed in South Africa, which is also required by most of the departments at TUT. The tool is managed by the student services department. The departments that require English Word Power book times for their students to come to use the computer lab at a scheduled time and in groups. The labs also have open hours where students who want extra time with the resource or students who are not required by their departments can come to use it. At UP, students have access to a 24-hour computer lab on campus. There are also small computer labs throughout campus and the residences. At UL there are many large computer labs. Also, some students have their own computers, but they mostly rely on these labs to complete and turn in assignments. At the UCC, there was a Multipurpose Language Complex being constructed which would constitute language labs for accommodating large classes; labs for graduate programs; rooms for multipurpose functions e.g. editing students' products, consultancy services; study rooms; computer labs; and language booths with links to the main console.

Language laboratories - The use of software and online resources seemed to have been one of the priority areas of almost all the universities visited. For example, as mentioned earlier TUT uses English Word Power (EWP), an online English instruction tool developed in South Africa, and managed by the student services department. The EWP program begins with an assessment, and then the platform automatically generates a module-based course of study that the student works through independently. They also have a scientific eye test machine called Visar Graph which deals with vision assessment. The vision assessment is a reading test with special goggles that determines reading speed and identifies how often a student stays on words, goes back, etc. The test is heavily used as a benchmark of English language skills by the university, and students are assigned a grade level from the results. Blackboard is available at all the universities in South Africa, but is not being used as an online learning management system - instead it is more of a document repository. At UP the academic literacy staff expressed interest in using Blackboard more effectively.

Also as noted earlier, at UL, Turn It In is available to staff, so that students can submit their assignments via email. At UCC a resource list of online resources is provided. There is an ICT centre for students to use computers. English Department at UCC also teaches how to make references on the internet. At UG, students' study materials are available online through KEWL system (similar to Blackboard), where students can download and print the materials in town. It would like to use more ICT based resources. In the semester prior to the visit, they tried Writing Planet, proprietary software but faced the challenge of lack of instructor commitment 
Towards re-defining communication skills courses at Sokoine University of Agriculture

to the system. Also they asked students to purchase the software individually but this was found to be difficult as the equipment was too expensive. They have an ICT Department and efforts are made towards developing custom online language resources.

Other facilities - There are other facilities, particularly at universities in Ghana, which have been found useful in aiding language learning or helping out the running of the language courses. At the UCC for example they use Radio FM to reach students, in that English lessons are sometimes broadcast on the University Radio Station. The Department of Communication Skills has a Risograph machine, which is instrumental in the production of high numbers of examination copies quickly and cost-effectively. UG has also a strong photocopying section, which can have 10 people making copies at a time.

Books and printed learning materials - The visited universities use guides, student workbooks, handouts, and pamphlets whereby the students not only get materials in the departmental library and the university library but also have access to online materials recommended to them by their instructors. The Language centre at the University of Ghana, for example, uses KEWL system which is similar to blackboard for putting up materials including teaching materials for students to download. The centre also uses the services of Language Planet-which is language learning based software. Using the software, the students can type their essay and marked instantly and identify problems and tell the instructor.

With respect to books and other learning materials, most of these are developed internally in all the visited universities. Also, at UCC alumni donate some used books to the departmental library. Nevertheless, focusing on learners' context is highly encouraged, for instance, TUT instructors have managed to adapt a Communication Skills book for Engineering (which is American) to suit learners' context. This is very crucial in arousing learners' motivation. It should be borne in mind that the five visited universities also have a range of comprehensive libraries, both at the departmental and university levels.

\section{Conclusion and recommendations}

Based on the findings of this study, the following conclusions and recommendations for SUA can be drawn: First, none of the universities visited used a placement examination in the way SUA does. Those that did so in the past have discarded these assessments as impractical and instead, mix students of varied abilities in classes. Instead of attempting to group students by learning levels, the trend observed is to group them by discipline and customize course material for relevance to the given discipline. Most universities attempt to have instructors specialize in a particular discipline, although labour turn over (staff shifting jobs) has been a problem. In addition, all the visited universities and most particularly, the University of Pretoria, expressed an interest in improving collaboration and sharing of best practices among African universities in the area of English language and communications skills. The University of Ghana, in particular, expressed its interest to collaborate, particularly in research and staff exchange.

Moreover, all the visited universities require students to complete two semesters of English language curriculum. This requirement is taken seriously and students are not allowed to continue registering for courses if they do not pass these classes. SUA could work towards making Communications Skills I a mandatory course and credited, where all students must take and pass. This would make students participate actively in learning the course, not only because it is a requirement to them, but also because of its value which would be a motivation for students to learn.

The other thing which isworth noting is that almost all the universities visited struggle with large class sizes. Obtaining the necessary number of permanent staff positions is often problematic, and thus the universities rely heavily on part-time staff. This reliance makes it difficult to recruit and retain instructors of the highest quality. Part-time arrangement was once practised at SUA for Communication Skills course. However, this arrangement proved unsustainable, especially because, apart from other problems related to remuneration package to the part-time staff, there was often no guarantee of getting the right type of instructors who are willing to render 
services at SUA. In this regard therefore, the University should continue to recruit new staff to be deployed to the Department.

Also, the staff at all the language departments visited were very collaborative. Most departments hold seminars or workshops before each semester to provide both training in teaching skills and methodologies and an opportunity for instructors to share challenges and best practices. This model would be very helpful to instructors at SUA, but in order for this model to work, there is need for a change of mind set among SUA instructors from other departments who believe that students' language problems at SUA can be fixed by Communications Skills instructors only. This mentality undermines the Department's efforts in improving students' communicative competence, because what is taught in Communication Skills classes is not emphasized in students other courses. Instructors from other disciplines need to realise that: first, they have a role to play in fostering what students have learned in language classes. Secondly, students in universities do not take Communication Skill courses just for the sake of them, but because they have to use the skills in following courses in their other disciplines. It is unfortunate to see Communication Skills courses in Tanzania universities being treated as pariah courses which have no connection whatsoever with other university courses.

Out of all the universities visited, only the University of Cape Coast has been able to integrate assessment of English language into other academic disciplines. Strategies that have helped them achieve this goal include the following: First, academic staff from all disciplines take into account language proficiency in the grading of assignments. This requires both interest and proficiency on the part of instructors, but results in students being more motivated to improve their English language and communications skills. Secondly, Instructors from other disciplines engage instructors from the Language Unit to assist in grading assignments for language when necessary. SUA could consider staff development initiatives for English language proficiency that would help create a similar learning environment. The University Teaching and Learning Improvement Program at SUA could be a starting point in moving towards this direction. Research in English as a second language in Tanzania (see Mohamed \& Banda, 2008; Ndoloi, 1990) has undoubtedly established that part of the students' language problems in higher education is also partly a result of instructors' deficiencies in language proficiency.

\section{References}

Brock-Utne, B., Desai, Z., \& Qorro, M. (Eds.) (2003) Language of instruction in Tanzania and South Africa. Dar-es-Salaam: E and D Publishers.

Brock-Utne, B., Desai, Z., \& Qorro, M. (Eds.) (2005). Language of instruction in Tanzania and South Africa. Dar-es-Salaam: E and D Publishers.

Brown, D. (2015) Teaching by principles: An interactive approach to language pedagogy. New York: Pearson Longman.

Ethnologue. (2005) Online. Retrieved from http://www.ethnologue.com/show_country.asp?name=Tanzania

Komba, S. (2008). The impact of communication skills course on students' development of communicative abilities. Unpublished Masteral dissertation, University of Dares Salaam, Tanzania.

Komba, S. C. (2015). The perceived importance of communication skills courses among university students: The case of two universities in Tanzania. International Journal of Education and Research, 3(2), 497-508.

Komba, S. C., Kafanabo, E. J., Njabili, A. F., \& Kira, E. S. (2012). Comparison between students' academic performance and their abilities in written English language skills: A Tanzanian perspective. International Journal of Development and Sustainability, 1(2), 305-325.

Mohamed, H. I., \& Banda, F. (2008). Classroom discourse and discursive practices in Higher Education in Tanzania. Multilingual and Multicultural Developments, 29(2), 95-109.

http://dx.doi.org/10.2167/jmmd548.0

Mohamed, H. I. (2005). Critical issues on the language of instruction in secondary and higher education in Tanzania. Uongozi Journal of Management Development Dynamics, 17(1), 32-51.

Mohamed, H. I. (2006). Academic writing as social practice: A critical discourse analysis of student writing in higher education in Tanzania. Unpublished Doctoral thesis, University of the Western Cape, Republic 
of South Africa.

Ndoloi, D. B. (1994) Writing like Tanzanians: Investigating the writing of first year students - University of Dar es Salaam. Unpublished Doctoral thesis, Lancaster University.

Qorro, M. A. S. (1999). A qualitative study on the teaching and learning of writing in English in Tanzania secondary schools in relation to the writing requirements of tertiary education. Unpublished Doctoral thesis, University of Dar es Salaam.

Richards, J., \& Rogers, T. (2001). Approaches and methods in language teaching. Cambridge. Cambridge University Press. http://dx.doi.org/10.1017/cbo9780511667305

Rugemalira, J. (1990). The communication skills unit and the language problem at the University of Dar es Salaam. In C. M. Rubagumya (Ed.), Language in education in Africa: A Tanzanian perspective (pp. 105-122). Clevedon: Multilingual Matters.

United Republic of Tanzania. (2014). Education and training policy. Ministry of Education and Vocational Training, Dar es Salaam. 
Komba, S. C., \& Mohamed, H. S. 